\title{
BIBLIOTECA VIVA EM HOSPITAIS: a importância da leitura como estratégia de humanização, a experiência do Instituto Fernandes Figueira
}

\author{
Carla Broseghini Moreira de \\ Carvalho \\ Bibliotecária do Hospital Regional de \\ Sobradinho da Secretaria de Estado \\ de Saúde do Distrito Federal. MBA \\ em Gestão Estratégica da Informação \\ pelo Centro Universitário do Distrito \\ Federal. \\ E-mail: carlahrs@gmail.com
}

\section{RESUMO}

O Projeto Biblioteca Viva em Hospitais (PBVH) é uma estratégia de humanização adotada por diversas instituições de saúde com o objetivo de levar à criança e ao adolescente hospitalizado a mediação de leitura de histórias infantojuvenis por intermédio de voluntários capacitados para tal função. O PBVH foi implantado em hospitais com atendimento pediátrico com o objetivo de humanizar o ambiente hospitalar e a assistência à criança hospitalizada, ou atendida em ambulatório. O Instituto Fernandes Figueira foi escolhido como objeto deste estudo por ser um dos pioneiros em implantar o PBVH no Rio de Janeiro. Uma vez internada a criança, ela é afastada do seio familiar, dos brinquedos, dos amigos e da escola. 0 objetivo deste trabalho é mostrar os benefícios da leitura mediada e a sua ação sobre o bem-estar de crianças hospitalizadas, a leitura como estratégia de humanização a fim de amenizar o sofrimento da comunidade infantil hospitalizada. Constatou-se que a mediação da leitura atenua situações de angústia e sofrimento de crianças internadas, ameniza a solidão hospitalar, ajuda também na relação da criança com as pessoas ao seu redor e sua socialização no hospital.

Palavras-chave: Humanização da assistência. Humanização dos serviços de saúde. Crianças - livros e leituras. Criança hospitalizada.

\section{LIVING LIBRARY IN HOSPITALS: the importance of reading as a humanization strategy, the experience of \\ Fernandes Figueira Institute}

\begin{abstract}
The Living Library in Hospitals (PBVH) is a humanization strategy adopted by many health institutions that aims to provide hospitalized children and adolescents with the mediation of infant-juvenile storybook reading by volunteers trained for this role. The PBVH has been deployed in hospitals with pediatric care to humanize the hospital environment and care for hospitalized or outpatient children. Fernandes Figueira Institute was chosen as an object of this study because it is one of the PBVH pioneers in Rio de Janeiro
\end{abstract}


in. When a child is admitted, she is removed from her family, toys, friends, and school. This study aims at showing the benefits of mediated reading and its effect on the well-being of hospitalized children, taking reading as a humanization strategy to relieve the suffering of hospitalized children. It proves that reading mediation reduces distress and suffering of hospitalized children, alleviates their loneliness in hospital, and helps improve the relationship of those children with people around them, and their socialization during admission.

Keywords: Humanization of assistance. Quality of human services. Children, books and reading for. Child, Hospitalized.

\section{INTRODUÇÃO}

O Programa Biblioteca Viva em hospitais (PBHV) surgiu a partir do trabalho em instituições de saúde, tais como hospitais e entidades de atendimento a crianças portadoras de deficiências. Ele faz parte do Núcleo de Apoio a Projetos Educacionais e Culturais (NAPEC) do Instituto Fernandes Figueira (IFF). É um espaço lúdico de leitura para bebês, crianças, jovens e acompanhantes, através do lazer e entretenimento. Foi criado com o intuito de formar mediadores de leitura e instalar espaços, com livros de literatura infantil e juvenil, em hospitais que atendem crianças com patologias variadas, promover a reconstituição de um espaço de vitalidade, de preservação e de desenvolvimento da saúde psíquica para as crianças em situação de internação hospitalar ou atendimento ambulatorial. Visa, assim, aumentar a aceitabilidade da criança ao tratamento e à situação de internação hospitalar, além de agregar situações estimuladoras ao processo de cura.

Para integrar o projeto, os voluntários participam de capacitações teóricas e práticas, em diferentes setores do IFF. Eles encontram as crianças, convivem com os médicos e enfermeiros, conhecem seus próprios limites dentro de um ambiente peculiar como um hospital. Superada essa etapa, são acomodados em áreas de acordo com o perfil do voluntário e as necessidades dos ambulatórios e enfermarias (MARTINS, 2016). Da Unidade de Pacientes Graves (UPG) aos ambulatórios, passando pelas enfermarias e outros setores do IFF, os voluntários da Biblioteca Viva tentam criar uma atmosfera mais leve, de preservação e desenvolvimento da saúde psíquica de todos através da leitura.

O projeto possui um acervo de literatura infanto-juvenil selecionado em cima de critérios de qualidade do texto e das ilustrações, bem como da diversidade quanto ao seu 
conteúdo, sem restrições temáticas. Esse acervo vai ao encontro das crianças através dos mediadores de leitura, que são voluntários, treinados de acordo com a rotina hospitalar e seus devidos cuidados.

A Biblioteca Viva não dispõe de recursos. A atualização do acervo é feita através de doações de editoras, de instituições e de particulares. 0 acervo do projeto conta hoje com mais de seis mil livros. São clássicos, de Os três porquinhos ou Chapeuzinho Vermelho e o Lobo Mau, a histórias de autores brasileiros infantis consagrados, como Ana Maria Machado, Ziraldo, Sílvia Orthof e outros. Os exemplares são agrupados em baús coloridos espalhados no hospital. Outra parte fica na sala do projeto, no ambulatório de Pediatria, que recebe as crianças que vão às consultas. Nos ambulatórios, a escolha dos livros é feita pelas crianças, num ambiente de descontração, sentadas em tapetes e almofadas coloridas emborrachadas. Nas enfermarias, os voluntários levam os livros até elas.

Os espaços de leitura propiciam o alívio de tensões e acarretam mudanças favoráveis no quadro psicológico das crianças, facilitando sua integração e de seus familiares com o corpo funcional do hospital, através da mediação de leitura. Permitem que crianças e jovens em situação de internação hospitalar tenham acesso a livros de qualidade e à leitura mediada; ampliam os espaços onde a leitura seja oferecida para as populações com menos acesso à leitura e menor possibilidade de aquisição de livros; facilitam a integração das crianças e de seus familiares com o corpo funcional do hospital, através da mediação de leitura; e propõem a leitura como forma de prazer, favorecendo, assim, a familiarização com os livros.

\section{METODOLOGIA}

O cenário escolhido para a pesquisa foi o Instituto Fernandes Figueira, por ser este um dos pioneiros em implantar o Projeto Biblioteca Viva em Hospitais - neste caso específico, no setor pediátrico de um hospital no Rio de Janeiro.

A abordagem da pesquisa foi de natureza qualitativa, sendo utilizado como instrumento de coleta de dados um questionário com duas perguntas abertas que avaliaram o efeito da mediação da leitura sobre as crianças. Os sujeitos da pesquisa foram os profissionais da saúde e voluntários que atuavam com as crianças. A primeira pergunta teve como objetivo verificar, através da percepção do profissional, se a leitura trouxe 
algum benefício na recuperação das crianças hospitalizadas. Já a segunda indaga se o profissional considera a leitura uma estratégia de humanização.

Em adição a esta coleta, foram selecionados e transcritos alguns dos depoimentos que foram registrados em um caderno da coordenação do PBVH do IFF, pelas pessoas que voluntariamente se oferecem para ler para as crianças hospitalizadas. 0 critério seletivo foi o registro que abordava as reações das crianças e dos acompanhantes durante a mediação da leitura.

Realizou-se também um levantamento em outras fontes de consulta, como folhetos, boletins, informativos, documentos institucionais, fotografias (acervo da coordenadora do $\mathrm{PBVH}$ ) e filmes que registram as atividades relacionadas ao $\mathrm{PBVH}$ do IFF.

Outra estratégia da pesquisa consistiu em uma pesquisa de campo utilizando a observação do cotidiano do cenário, pela autora do estudo, a fim de concluir o presente trabalho. Essa observação foi realizada de forma tácita, por meio de visitas coordenadas, durante as quais se observou que permitiram verificar como se efetuavam as atividades de mediação da leitura desenvolvida pelos voluntários nos espaços do hospital.

Com a finalidade de preservar o anonimato dos participantes, estabeleceu-se que seriam trocados os nomes dos profissionais da saúde e dos voluntários por nomes de personagens da literatura infantil e nomes de super-heróis de quadrinhos, a fim de mostrar que muitos desses personagens enfrentaram grandes obstáculos antes de triunfar contra o mal.

\section{HUMANIZAÇÃO E A SAÚDE DAS CRIANÇAS}

Uma vez internada a criança, ela é afastada do seio familiar, dos brinquedos, dos amigos e da escola. Esse afastamento gera um sentimento de culpa, desenvolvendo fobias, depressão, hiperatividade e por vezes perdendo seu referencial.

As crianças de dois ou três anos sentem que a sua hospitalização é um abandono por parte dos pais, enquanto as crianças de quatro ou seis anos já a consideram como um castigo por algo que tenham feito. Mesmo as crianças de 10 ou 12 anos podem sofrer a hospitalização como situação de grande ansiedade, embora já tenham capacidade de racionalmente compreender sua necessidade. (MACHADO, 1991, p.13). 
Oliveira (1997) entrevistou crianças hospitalizadas de cinco a 11 anos de idade. Dessas entrevistas, saiu como categoria um conjunto de representações do hospital. Segundo as crianças, o hospital é: desconhecido, estranho; sem nada "legal", em oposição à escola; sem possibilidade de atividades ao ar livre; proibição de brincar; anonimato; evita a morte em casa; lugar de torturas, suplícios e agressões físicas com intenções punitivas; solidão, tristeza e saudade.

Ceccim (1997) corrobora esta opinião e afirma que o hospital e a enfermidade produzem, para a criança, uma relação peculiar com o mundo, onde o cuidado, a cura e os atos de saúde requerem uma abordagem mais integral.

[...] representam, no mínimo, uma forte ameaça à sua integridade emocional. [...] passam por seu corpo e emoções: passam por sua cultura e relações; produzem afetos e inscrevem conhecimentos sobre si, o outro, a saúde, a doença, o cuidado, a proteção, a vida. (CECCIM, 1997, p.33).

Acredita-se ser a humanização alcançada em ambiente hospitalar, através do trabalho recreativo em unidades pediátricas, contribuindo para o bem-estar da criança, propiciando o alívio de tensões e mudanças favoráveis no seu quadro psicológico, e sua socialização no hospital, local totalmente desconhecido para a criança.

\section{LEITURA COMO ESTRATÉGIA DE HUMANIZAÇÃO}

A Resolução no. 41, art. 9, do Ministério da Justiça e do Conselho Nacional dos Direitos da Criança e do Adolescente, data de outubro de 1995 (BRASIL, 1995), prevê que toda criança e adolescente hospitalizado tem o direito de desfrutar de alguma forma de recreação, programas de educação para a saúde e acompanhamento de currículo escolar durante sua permanência hospitalar. Portanto, os hospitais que recebem crianças devem dispor de um local e de profissionais capacitados para desenvolver junto com elas um momento de recreação, um momento lúdico.

Tal resolução leva em conta a necessidade das crianças e adolescentes superarem os traumas causados por uma internação temporária e - em casos mais graves permanente. 0 hospital é um lugar que causa medo, estando muitas vezes relacionado com a dor e a morte. A doença acaba excluindo a criança de seu ambiente, imobilizando-a social e intelectualmente. 
Muitos estudos têm demonstrado que a hospitalização pode afetar o desenvolvimento infantil. 0 ambiente hospitalar, associado à dor física, distanciamento da família, dos brinquedos, dos amigos, da escola e a submissão a procedimentos desconhecidos e dolorosos traz muitas situações novas e angustiantes com as quais a criança vai ter que se deparar e enfrentar.

A identidade de ser criança é, muitas vezes, diluída numa situação de internação, em que a criança se vê numa realidade diferente da sua vida cotidiana. 0 papel de ser criança é sufocado pelas rotinas e práticas hospitalares que tratam a criança como paciente, como aquele que inspira e necessita de cuidados médicos, que precisa ficar imobilizado e que parece alheio aos acontecimentos ao seu redor (FONTES, 2005, p.119).

Preocupados com essa situação e apostando em um trabalho de equipe com voluntariado, o Projeto Biblioteca Viva em Hospitais foi implantado no Instituto Fernandes Figueira por se acreditar que, por meio da leitura de histórias, da identificação de personagens, rir, emocionar-se com os contos, ver painéis e imagens contidas no livro, se alcançaria, através da leitura, a humanização; o lúdico amenizaria o sofrimento dessas crianças, além de socializá-las no ambiente hospitalar.

Segundo Vieira (2002 apud CERIBELI, 2009), o hospital, para a criança, é um ambiente diferente, desconhecido e muitas vezes assustador, e a separação da sua família, causada pela hospitalização, pode acarretar severos traumas emocionais, levando-as a apresentar comportamentos agressivos, como raiva e violência, ou choro constante, seguidos de angústia e depressão, dificuldades de aprendizagem e retardo de desenvolvimento.

Para Pierdoná (2007, p. 26), as histórias contribuem para facilitar a comunicação das crianças com a equipe médica, aumenta a autoestima, estimula a criatividade das crianças, aliviando, assim, as tensões diárias e facilitando a socialização.

A mediação da leitura pode também servir como forma de comunicação com a criança hospitalizada, pois torna possível a relação mais intuitiva, por facilitar a comunicação não verbal. Para Bettelheim (2002), através das fábulas e dos contos fantásticos, acessíveis à sua compreensão, as crianças desafogam emoções fortes como raiva, medo, dor e sofrimento. Os livros são apresentados à criança, podendo despertar ou não interesse pela história. E cabe ao mediador respeitar sua vontade e o tempo em que ela deseja para ouvir as histórias. 
Ceribelli et al. (2009) acrescentam que o hospital não é um local só de dor e sofrimento; nele sempre há espaço que deve ser aproveitado para o desenvolvimento de atividades pedagógicas e recreacionais, pois a internação não deve interromper o processo de desenvolvimento infantil.

Mazzillo (2007, p. 29) ressalta que o encantamento das histórias contadas leva às crianças a momentos de paz e liberdade, uma pausa no sofrimento, a possibilidade de transpor as barreiras físicas do hospital.

Caldin (2001) relata em seu trabalho realizado em um hospital universitário, que a psicóloga que acompanhava de perto as atividades de leitura consideravam válida as leituras de contos para as crianças, porque elas se esqueciam da condição de enfermas e se sentiam relaxadas ao escutar uma narrativa funcional. Destaca também que as atividades lúdicas e recreativas são responsáveis pela ativação de recursos do organismo e liberação de substâncias que atenuam a dor - portanto, tais atividades são consideradas terapêuticas.

Para Santanna, Gregório e Gerlin (2014) o ambiente hospitalar também pode utilizar a leitura como ação aliviadora do sofrimento decorrido com as enfermidades acometidas a pacientes. Eles ainda ressaltam que o trabalho com leitura no hospital comumente ocasiona alívio da tensão causada por procedimentos invasivos, que são característicos desse ambiente.

\section{RESULTADOS}

Os resultados das perguntas respondidas pelos profissionais da saúde, os trechos das falas do documentário "O bom jeitinho brasileiro" (2008) e os depoimentos do caderno de registros do IFF mostram, através das falas desses sujeitos, ${ }^{1}$ várias unidades de sentido, onde no geral se constata que a leitura no ambiente hospitalar ameniza o sofrimento da criança hospitalizada, sendo considerada também uma estratégia para humanização.

\footnotetext{
${ }^{1}$ Foram mantidas as expressões que denotam intensidade ou sentimentos do indivíduo, buscando preservar tais características no discurso dos sujeitos. Além disso, buscou-se também sinalizar, com a utilização de colchetes, aspectos das falas que estavam implícitos na conversa.
} 
Após a análise na literatura científica, também foi possível identificar a importância social da leitura como estratégia de humanização nos hospitais pediátricos por parte dos profissionais da saúde, uma vez que essa iniciativa tem tornado mais alegres os dias já tão difíceis e dolorosos das crianças e adolescentes internados. Essa importância evidenciou-se na nítida percepção da melhora do humor das crianças após as sessões de leitura e atividade lúdicas. As crianças ficaram mais desinibidas e até aceitaram as medicações com mais facilidade.

A reação dos profissionais da saúde, funcionários, acompanhantes é favorável ao projeto. Eles aceitam a leitura como fazendo parte do processo de tratamento, como uma ação que envolve outros tipos de conhecimento e abordagem, fora do domínio puramente tecnológico.

A leitura aumenta a aceitabilidade das crianças ao tratamento e a internação:

A leitura proporciona um momento de prazer, faz parte do processo terapêutico. Existe uma mudança da criança em relação às pessoas e o ambiente do hospital. Aumenta a aceitabilidade das crianças ao tratamento e a internação. A leitura humaniza porque as crianças são privadas dos prazeres de fora do hospital, e com a leitura elas são colocadas em contato com o lúdico, com a fantasia. (Fonoaudióloga Moranguinho).

Ao ler para o M. na Cirurgia fiquei super feliz. Mesmo todo amarrado e cheio de fios, ele sorriu para a história do Pooh. Conforme eu lia, mas ele sorria. (Voluntária Princesa Sofia)

A leitura aumenta o conhecimento da criança, o hospital se torna um ambiente mais leve:

Várias mães me dizem que acha o projeto muito bom porque alivia o estresse das crianças, deixando-as mais alegres e menos incomodadas com o ambiente. (Voluntária Dona Benta).

Nos momentos em que as crianças ouvem as histórias, os olhos dela brilham, as crianças passam a sorrir. A leitura humaniza porque ela se sente alguém, ela não se vê como mais um paciente, a leitura socializa essa criança no ambiente hospitalar. (Nutricionista Pucca).

A leitura fornece sentimentos de alegria, relaxamento, de socialização:

As crianças adoram ver os voluntários chegando com os livros para contar histórias para elas. A gente vê a diferença na criança, no rostinho delas, no jeito de como elas recebem os voluntários. Elas ficam mais felizes ao ouvir 
as histórias. É o tempo todo perguntando: Ninguém vem contar história hoje? Onde estão os livros? Estou esperando a história, eu quero os livros... (Enfermeira Dora Aventureira).

A mãe colocou C. sentada na sala de leitura e me disse: "Que bom que você está aqui! Quando lá em casa falamos em vir ao IFF, C. sempre fala que adora vir, pois tem as tias que leem livros para ela". (Voluntária Mulher invisível).

Eu estava lendo para uma criança dos seus 7 anos na enfermaria da cirurgia, quando ela me disse que estava muito feliz pois estava adorando as historinhas contadas por mim, ela também disse que nem se lembrava que estava dentro de um hospital. (Voluntária Sininho).

A leitura mostra benefícios como o bem-estar dos pacientes e melhor relação pais, filhos e acompanhantes:

A frequência cardíaca se torna mais baixa, melhora o padrão respiratório das crianças submetidas a ventilação mecânica no momento em que ouvem as histórias. A leitura humaniza porque torna o ambiente do hospital mais agradável, muito pais também passam a ler histórias e isso aumenta a qualidade da relação pais e filhos. (Dra. Pediatra Peppa).

A leitura humaniza, oferece suporte emocional:

Os pacientes aqui do hospital têm uma característica de terem doenças mais complicadas, de difícil resolução. Isso imprime uma situação de estresse muito grande, então essas situações de leitura, de tirar o pensamento da doença, de tirar aquele envolvimento da hospitalização, dos assuntos relacionados a hospitalização, conduzindo a criança para um momento do lúdico e da leitura, isso é coadjuvante no tratamento. Eu digo para você resumidamente que eu preciso tanto de um aparelho, um tomógrafo de última geração quanto da Magdalena (Coordenadora do Projeto Biblioteca Viva) com os livros dela junto das crianças. (Dr. Pediatra Homem Aranha).

É difícil mensurar uma coisa subjetiva que é esse trabalho (de leitura) que os voluntários fazem, mas com toda a certeza você vê a felicidade das crianças quando essas pessoas chegam. Eu acho sensacional o trabalho de todos eles porque eu acho que a gente acaba se tocando que tem vida fora do hospital, e dentro do hospital, às vezes você está tão envolvido com a patologia da criança, com a doença da criança que você esquece disso, que você tem que ver a criança das formas mais completas, que ela vive em casa, ou seja, brinca, canta, dança e lê. (Dr. Pediatra Homem de Ferro)22.

\footnotetext{
2 "O Bom Jeitinho Brasileiro" é uma minissérie do Canal Futura com diversos episódios que contam a história de brasileiros comuns, anônimos, que usam o " jeitinho brasileiro" para deixar a vida mais colorida, mais bonita e mais inspiradora.
} 
Melhora a aceitabilidade de procedimentos dolorosos:

A presença dos voluntários com os seus livros de histórias faz toda a diferença. $O$ ato voluntário por si só já é um ato de amor, e eles se doam para as crianças que precisam tanto desse carinho. As crianças sentem a falta deles a cada momento em que eles não estão aqui. A leitura tem tido uma função importante na melhoria da qualidade de vida, aceitação dessas crianças em relação ao tratamento. (Dr. Pediatra Batman).

Uma vez no Raio $X$ tinha um número de crianças pequenas na faixa de 1 a 2 anos de idade. Fui até elas porque choravam muito devido a colocação da seringa com medicação. Com os livros de bichinhos foram se acalmando e esqueceram das seringas. (Voluntária Mulher Maravilha).

Resgata o sonho e o imaginário

A ansiedade é um fator muito forte aqui na enfermaria, no pós-operatório das crianças e dos pais. A leitura de história para as crianças é importante porque ela tira o foco das crianças da ansiedade, na realidade a ansiedade é desviada... e nesse pequeno momento de interação leitura e criança, elas podem refletir em coisas maravilhosas e fantasiosas, elas podem sonhar... (Enfermeira Luna)

A minha impressão diária ao observar essas crianças em contato com a leitura é que elas se aproximam de uma realidade boa, criadas por elas mesmas. Tem crianças daqui que só conhecem uma árvore pelos livros. A leitura humaniza porque ela torna o ambiente mais leve, possibilita que a criança saia por um momento do sofrimento do hospital ao se encontrar com o lúdico. Traz também outros indivíduos (voluntários) que não são da área de saúde com outro olhar [...] é um reforço na equipe. (Fisioterapeuta Cinderela)

\section{CONSIDERAÇÕES FINAIS}

Foram observados, a partir da literatura estudada para a realização deste trabalho, os efeitos benéficos da leitura para crianças que ficam internadas no hospital por um longo período de tempo. Tal atividade alivia as tensões criadas pela rotina hospitalar que causam o estresse tanto das crianças enfermas quanto dos acompanhantes.

A hora das histórias é uma hora mágica; nota-se que proporciona uma viagem ao mundo imaginário. A alegria toma conta das crianças quando lhes é anunciado: "Agora, vou contar uma história!". A atenção se concentra e fortifica. O "Era uma vez...", no dizer preciso dos voluntários do $\mathrm{PBVH}$, levanta a cortina de um mundo novo, que escapa à realidade imediata. Observa-se que o desconforto e a dor cedem lugar às risadas. É 
gratificante observar as expressões faciais cheias de sorrisos e curiosidades, apresentando certo alívio das pressões emocionais enquanto dura a narrativa.

A escolha da criança da obra a ser lida, a forma de interação e divertimento que esse ato tão simples provoca nas crianças que se encontram internadas representa algo extremamente gratificante e recompensador.

Os voluntários procuram retirar o sorriso na dor, levantar a autoestima da criança e da família, através do universo lúdico das histórias e brincadeiras, transformando o período de internação mais leve, e dessa forma ajudando as crianças em aceitar o tratamento.

Espera-se que todo o desalento provocado pela hospitalização não tenha como remédios tão somente as paredes e tetos brancos, não só o leito com pensamentos de medo, ansiedade, monotonia. A introdução de atividades de humanização no contexto dos hospitais pediátricos deve ser uma prioridade. A leitura como estratégia de humanização, pode trazer efeitos positivos para as crianças hospitalizadas. A leitura terapêutica às crianças hospitalizadas é uma estratégia de cuidado humanizado na atenção integral à saúde. Afinal, as crianças internadas, em geral, estão submetidas a pressões e desconfortos psicológicos inerentes muitas vezes à fragilidade emocional desencadeada pelo processo patológico.

A prática de atividades lúdicas deve ser implementada em hospitais pediátricos para melhor adaptação de crianças e adolescentes a esse ambiente hostil. Esse tipo de prática é um instrumento capaz de aliviar dor e tensão a que as crianças hospitalizadas estão submetidas. Nesse contexto, a leitura como estratégia de humanização merece destaque, pois contribui não só para amenizar a solidão hospitalar, sendo também essencial para aprimorar a relação da criança com as pessoas ao seu redor, sua socialização no hospital, facilitando a adesão ao tratamento.

\section{REFERÊNCIAS}

SANTANNA, J.; GREGÓRIO, E. M.; GERLIN, M. N. M. Atuação bibliotecária além da biblioteca: o espaço de leitura do Hospital Universitário Cassiano Antônio de Moraes (Hucam). Revista ACB: Biblioteconomia em Santa Catarina, Florianópolis, v. 19, n. 1, p. 77-88, jan./jun. 2014.

BETTElheim, B. A psicanálise dos contos de fadas. 16. ed. Rio de Janeiro: Paz e Terra, 2002. 
BRASIL. Conselho Nacional dos Direitos da Criança e do Adolescente. Resolução n4, de 13 de outubro de 1995. Direitos da criança e do adolescente hospitalizados. Diário Oficial [da] República Federativa do Brasil, Poder Executivo, Brasília, DF, 17 out. 1995.

CALDIN, C. F. A leitura como função terapêutica: biblioterapia. Revista Eletrônica de Biblioteconomia, Florianópolis, v.6, n.12, p. 32-44, 2001.

CECCIM, R. B. Criança hospitalizada: a atenção integral como uma escuta à vida. In: CECCIM, R. B.; CARVALHO, P. R. A. (Org.). Criança hospitalizada: atenção integral como escuta à vida. Porto Alegre: UFRGS, 1997. p. 27-41.

CERIBELLI, C. et al. A mediação de leitura como recurso de comunicação com crianças hospitalizadas. Revista Latino-Americana de Enfermagem, Ribeirão Preto, v.17, n.1, p. 81-87, jan./fev. 2009.

FONTES, R. S. A escuta pedagógica à criança hospitalizada: discutindo o papel da educação no hospital. Revista Brasileira de Educação, n. 29, p. 119-138, maio/ago. 2005.

MACHADO, D. V. M. Higiene mental. In: MARCONDES, E. Pediatria básica. 8. ed. São Paulo: Savier, 1991. v.1, p. 108-113.

MAZZILLO, C. A. A liberdade de sonhar. In: KETZER, S. M.; AMODEO, M. T. (Org.). Histórias para ouvir, criar e contar: inventar ajuda a curar. Porto Alegre: EDIPUCRS, 2007. p. 28-29.

O bom jeitinho brasileiro. Direção: Antonio Andrade. Rio de Janeiro: Canal Futura, 2008.

Disponível em: <https://www.youtube.com/watch?v=xuf2ZzUsgss>. Acesso em: 4 fev. 2017.

OLIVEIRA, H. Ouvindo a criança sobre a enfermidade e a hospitalização. In: CECCIM, R. B.;

CARVALHO, P. R. A. (Org.). Criança hospitalizada: atenção integral como escuta à vida. Porto Alegre: UFRGS, 1997. p. 42-55.

MARTINS, E. 0 doce remédio da leitura: voluntários e literatura mudam a realidade de crianças no Instituto Fernandes Figueira. 0 Globo, Rio de Janeiro, 9 abr. 2016. Disponível em:

<https://oglobo.globo.com/rio/o-doce-remedio-da-leitura-1-15812291\#ixzz4ybeVNYqqstest>. Acesso em: 15 fev. 2017.

PIERDONÁ, J. Está na hora. In: KETZER, S. M.; AMODEO, M. T. (Org.). Histórias para ouvir, criar e contar: inventar ajuda a curar. Porto Alegre: EDIPUCRS, 2007. p. 26-27.

VIEIRA, M. A.; LIMA, R. A. G. Crianças e adolescentes com doença crônica: convivendo com mudanças. Revista Latino-Americana de Enfermagem, Ribeirão Preto, v. 10, n. 4, p. 552-560, jul./ago. 2002.

Recebido em: 28 de junho de 2017

Aceito em: 22 de novembro de 2017 